\title{
The distribution of human rectal aberrant crypt foci and criteria for defining the counting area
}

\author{
TETSURO FUJII, EIJI SAKAI, HIROKAZU TAKAHASHI, EIJI YAMADA, \\ HIDENORI OHKUBO, TAKUMA HIGURASHI and ATSUSHI NAKAJIMA \\ Department of Gastroenterology and Hepatology, \\ Yokohama City University School of Medicine, Yokohama, Kanagawa 236-0004, Japan
}

Received July 4, 2016; Accepted March 29, 2017

DOI: $10.3892 / \mathrm{ol} .2017 .6003$

\begin{abstract}
Aberrant crypt foci (ACF) are considered as a useful surrogate biomarker for colorectal cancer, although their biological significance still remains controversial. We conducted this study to clarify whether differences in the ACF counting area might have led to the discrepancies in the ACF counts among previous reports. A endoscopist proficient in ACF counting performed high-magnification chromoscopic colonoscopy in 45 subjects and investigated the distribution of ACF in four bowel segments (middle Houston valve to the dentate line and distal rectum 0-5, 5-10 and 10-15 cm). We also investigated whether the patient physique might affect the distance from the middle Houston valve to the dentate line. The prevalence of ACF was $84 \%$ and most of the ACF (170/210, $81 \%$ ) were located in the bowel segment from the middle Houston valve to the dentate line. The number of ACF was significantly correlated with the bowel segment in which the counting was performed: Dentate line to the middle Houston valve and distal rectum within $0-15 \mathrm{~cm}(\mathrm{r}=0.94, \mathrm{P}<0.001)$. The patient physique did not affect the distance from the middle Houston valve to the dentate line. In conclusion, the definition of the ACF counting area may not affect the results of ACF counting.
\end{abstract}

\section{Introduction}

Although colonoscopic screening and subsequent endoscopic resection of preneoplastic lesions, such as colorectal adenoma,

Correspondence to: Dr Atsushi Nakajima, Department of Gastroenterology and Hepatology, Yokohama City University School of Medicine, 3-9 Fuku-ura, Kanazawa-ku, Yokohama, Kanagawa 236-0004, Japan

E-mail: nakajima-tky@umin.ac.jp

Abbriviations: CRC, colorectal cancer; ACF, aberrant crypt foci; BMI, body mass index

Key words: aberrant crypt foci, high-magnification chromoscopic colonoscopy, colorectal carciogenesis have been reported to be effective for reducing the incidence of colorectal cancer (CRC) (1), CRC still remains one of the most common causes of cancer-related death in developed countries (2). Recently, aberrant crypt foci (ACF) have emerged as a putative precursor to colorectal adenoma, and have been suggested to be a potentially useful biomarker for $\mathrm{CRC}$. ACF were initially identified as the earliest recognizable lesions on the colonic mucosa in rodents exposed to colorectal carcinogens (3) and their presence has been demonstrated to be an important predictor of CRC (4-6). Shortly after the description in animals, ACF were also identified in the human colonic mucosa, using methylene blue staining $(7,8)$. Although several previous epidemiological studies have revealed significant associations between the prevalence and/or number of $\mathrm{ACF}$ and the synchronous presence of advanced neoplasms, including both adenoma and CRC (8-16), others have reported a lack of such correlation $(17,18)$. Therefore, the biological significance of human ACF still remains to be established.

These discrepancies among previous reports may be explained, at least in part, by differences in the participant characteristics, such as race, age and behavioral factors. In addition, it is considered that variations in the criteria for defining the ACF counting area may also be possibly associated with these discrepancies. In some studies, the counting of $\mathrm{ACF}$ was carried out in the region from the middle Houston valve to the dentate line $(8,16,17,19)$. On the other hand, in other studies, the counting was carried out in the distal rectum up to $10-15 \mathrm{~cm}$ from the dentate line (9-11,13-15). Cho et al defined the examination area as the entire rectum (18). Since such differences affect the interpretation of the results of previous reports, we conducted this study to clarify whether the criteria used to define the counting area for ACF may affect the number of ACF.

\section{Materials and methods}

Patients. The patients who underwent a total colonoscopy and counting of ACF at the Yokohama City University Hospital from May to August 2014 were eligible to participate in this study. All the procedures were performed by one endoscopist proficient in ACF counting (S.E.). The exclusion criteria were as follows; patients with a history of familial adenomatous polyposis, hereditary non-polyposis CRC, inflammatory 
Table I. Patient characteristics.

\begin{tabular}{lcccr}
\hline Characteristics & Normal subjects & Adenoma patients & CRC patients & P-value \\
\hline Number of subjects & 20 & 19 & 6 & \\
Age, mean \pm SD & $62.4 \pm 10.5$ & $65.6 \pm 9.8$ & $69.2 \pm 6.9$ & N.S. \\
Sex, male/Female & $11 / 8$ & $13 / 7$ & $4 / 2$ & N.S. \\
Presence of ACF & & & & \\
Total number & 42 & 109 & 59 & \\
Prevalence, $(\%)$ & $15 / 20(75)$ & $17 / 19(89)$ & $6 / 6(100)$ & N.S. \\
Mean \pm SD & $2.1 \pm 1.9$ & $5.7 \pm 2.5$ & $9.8 \pm 10.1$ & $<0.01$ \\
\hline
\end{tabular}

CRC, colorectal cancer; ACF, aberrant crypt foci; SD, standard devition.

bowel disease, radiation colitis, history of previous surgical or endoscopic resection of colonic adenomas and/or cancer, current invasive cancer, prior large-bowel resection, except appendectomy. Of 68 patients received total colonoscopy, 6 patients without informed consent were excluded in addition to the aforementioned exclusion critetria. Finally a total of 45 subjects were prospectively enrolled in this study. The patients were divided into three groups according to the presence of colorectal tumors; normal subjects, adenoma patients and CRC patients. The study was conducted with the approval of the Yokohama City University Hospital Ethics Committee. Written informed consent was obtained from all the subjects prior to their participation in the study.

Criteria used for endoscopic diagnosis of ACF. ACF are identified as clusters of crypts that stain darker than the surrounding normal mucosa. Larger sizes of the crypts, raised appearance, thicker epithelial lining, dilated or slit-like crypt lumina, and increased pericryptal area as compared to the surrounding normal mucosa are the most frequently used criteria to identify ACF (8).

Magnifying endoscopy. All subjects were asked to drink 2,000 $\mathrm{ml}$ of polyethylene glycol-based solution as a bowel preparation measure prior to the endoscopic examination. If the bowel cleaning was insufficient, an additional polyethylene glycol-based solution was administered. Total colonoscopy was performed before the examination for the ACF. A Fujinon EC-490ZW5/M colonoscope was used for the high-magnifying chromoendoscopy (Fujifilm Medical Co., Ltd., Tokyo, Japan). Methylene blue dye (0.2\%) was applied to coat the mucosal surface, followed by adequate washing with warm tap water. After 2 min of staining the mucosa, the excess dye was removed carefully by washing with water, and then observation for ACF was commenced. We counted the number of ACF in two defined areas; from the dentate line to the middle Houston valve (definition 1) and the distal rectum extending $15 \mathrm{~cm}$ from the dentate line (definition 2). The distribution of ACF was evaluated in four bowel segments (middle Houston valve to the dentate line, and the distal rectum $0-5,5-10$ and $10-15 \mathrm{~cm}$ ). To prevent double counting, the ACF were counted in a sequential fashion during a single withdrawal of the endoscope.
Statistical analysis. The numbers of ACF was compared among the three groups (normal subjects, adenoma patients and CRC patients) using the Kruskal Wallis test. The correlation of the number of ACF with the criteria for defining the ACF counting area was evaluated by Pearson's correlation coefficient. The relationship between the distance from the middle Houston valve to the dentate line and the patient physique (gender, height and BMI) was also evaluated by Pearson's correlation coefficient. Unless otherwise specified, P-values $<0.05$ were considered to denote statistical significance. All the analyses were performed using the SPSS statistical package (version 11.0; SPSS, Inc., Chicago, IL, USA).

\section{Results}

Patients characteristics. The patients characteristics are shown in Table I. The prevalence of ACF was $84 \%$ and the number of ACF was 4.7 \pm 5.7 . Consistent with previous studies (11-14), the number of $\mathrm{ACF}$ in the distal rectum extending $15 \mathrm{~cm}$ from the dentate line was significantly higher in the CRC patients than in the normal subjects and/or adenoma patients (the number in normal subjects, adenoma patients and CRC patients, 2.1 \pm 1.9 , $5.7 \pm 2.5$ and $9.8 \pm 10.1$, respectively, $\mathrm{P}<0.01$ ).

The distribution of ACF and number of ACF depending on the criteria used for defining the ACF counting area. The distribution of the ACF is shown in Table II. In all enrolled patients, the middle Houston valve was located within $15 \mathrm{~cm}$ from the dentate line. The average distance from the middle Houston valve to the dentate line was $8.5 \pm 1.3 \mathrm{~cm}$. Most of the ACF $(170 / 210,81 \%)$ were located in the bowel segment from the middle Houston valve to the dentate line. There were few dispersion of the ACF number regardless of the different definition of counting area. $(r=0.94, \mathrm{P}<0.001)$ (Fig. 1), suggesting that such descrepancy may not affect the interpretation of the results of previous studies (8-19).

Correlation between the patient physiques and the length of the bowel segment from the dentate line to the middle Houston valve. The height of the participants was $165.8 \pm 7.2 \mathrm{~cm}$ (male, 167.5 \pm 6.0 ; female, $155.0 \pm 4.2, \mathrm{P}<0.01)$ and the BMI was $23.4 \pm 2.7 \mathrm{~kg} / \mathrm{m}^{2}$ (male, $23.3 \pm 2.5$; female, $24.3 \pm 4.0, \mathrm{P}=0.77$ ). Gender was not associated with the length of the bowel 
Table II. Distribution of ACF.

\begin{tabular}{|c|c|c|c|c|}
\hline \multirow[b]{3}{*}{ Variable } & \multicolumn{4}{|c|}{ Bowel segment } \\
\hline & \multirow{2}{*}{$\frac{\text { Definition } 1}{\text { Dentate line-middle Houston valve }}$} & \multicolumn{3}{|c|}{ Definition 2} \\
\hline & & $0-5 \mathrm{~cm}$ & $5-10 \mathrm{~cm}$ & $10-15 \mathrm{~cm}$ \\
\hline ACF number & 170 & 77 & 105 & 28 \\
\hline
\end{tabular}

In all enrolled patients, the middle Houston valve was located within $15 \mathrm{~cm}$ from the dentate line. ACF, aberrant crypt foci.

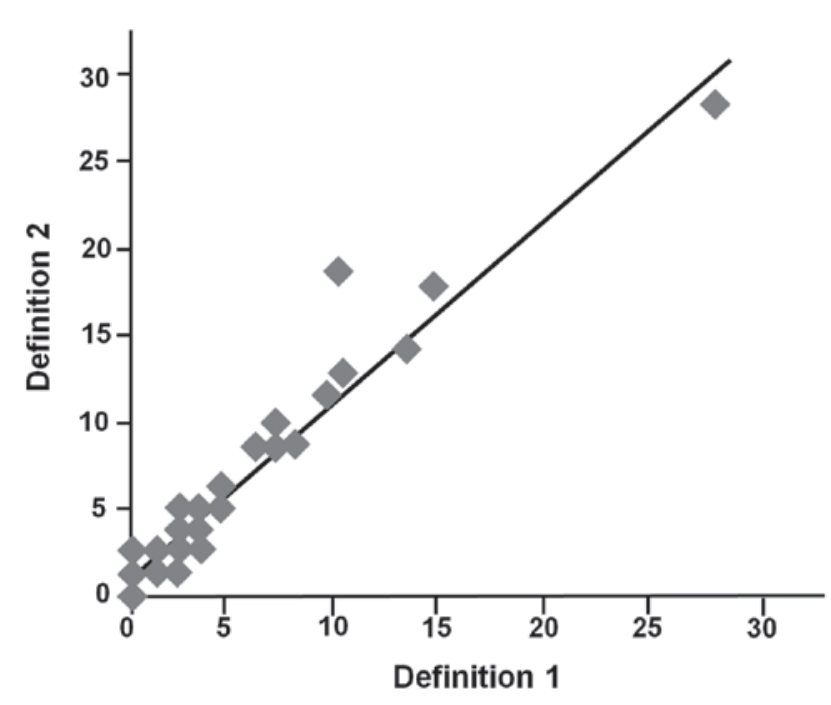

Figure 1. Correlation between the number of aberrant crypt foci from the dentate line to the middle Houston valve (definition 1) and that in the bowel segment within $15 \mathrm{~cm}$ from the dentate line (definition 2$)(\mathrm{r}=0.94, \mathrm{P}<0.001)$.

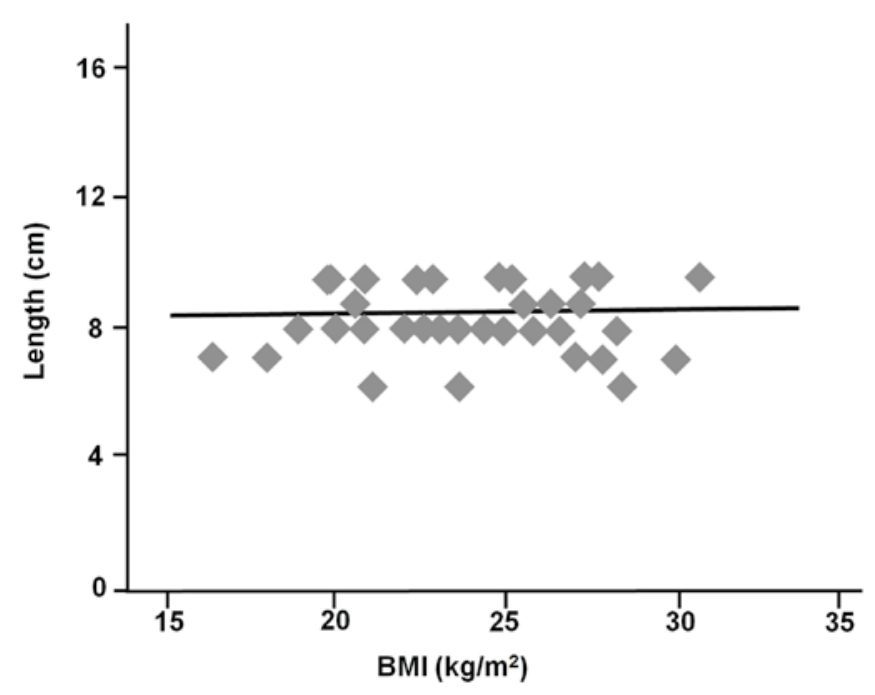

Figure 2. Correlation between the body mass index (BMI) and length of the bowel segment from the dentate line to the middle Houston valve $(r=0.002$, $\mathrm{P}=0.99$ ).

segment from the middle Houston valve to the dentate line (male, 8.4 \pm 1.3 ; female, 9.2 $\pm 1.1, \mathrm{P}=0.90)$. In addition, the height $(\mathrm{r}=-0.18, \mathrm{P}=0.28)$ and $\mathrm{BMI}(\mathrm{r}=0.002, \mathrm{P}=0.99)$ were also not correlated significantly with the length of the bowel

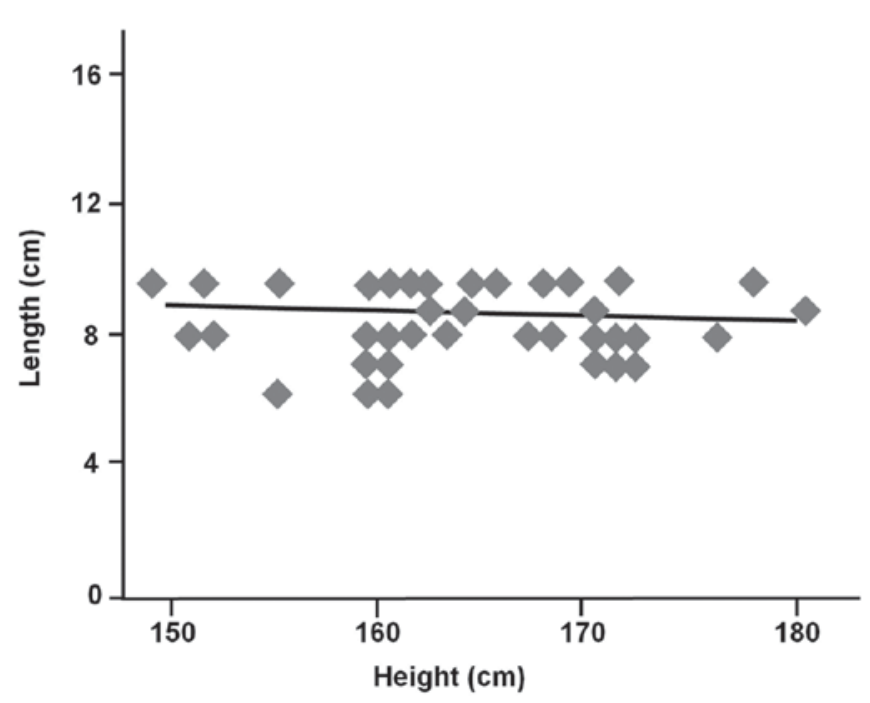

Figure 3. Correlation between the height and the length of the bowel segment from the dentate line to the middle Houston valve $(\mathrm{r}=-0.18, \mathrm{P}=0.28)$.

segment from the middle Houston valve to the dentate line (Figs. 2 and 3).

\section{Discussion}

To evaluate the efficacy of chemopreventive agents in CRC chemoprevention trials, reliable surrogate biomarkers are required. Recently, several trials have been conducted using the presence of ACF as the endpoint (18-21). Our recent large scale epidemiological study demonstrated that ACF may serve as a reliable surrogate biomarker for CRC in humans (18). On the other hand, a multicenter study conducted in the US by Mutch et al raised serious questions about whether ACF can be used as a surrogate biomarker for CRC (17). To establish the clinical significance of ACF, it is important to determine the cause of this aforementioned discrepancy in interpretation among previous studies.

In most of previous studies, while the ACF were identified by high-magnification chromoscopic colonoscopy using the same dye (methylene blue) and same criteria for endoscopic detection, the criteria used to define ACF counting area during colonoscopy differed among studies. Therefore, we hypothesized that differences in the ACF counting area may be the reason for the discrepancies in the interpretation of the clinical significance of ACF among previous studies. Our results revealed that differences in the counting area did not 
affect the results of ACF counting, because most ACF were located in the bowel segment from the middle Houston valve to the dentate line. As we confirmed that the results of ACF counting did not differ significantly between the two different ACF counting areas most frequently used in previous studies: The region from the middle Houston valve to the dentate line $(8,16,19,22)$ and the distal rectum up to $15 \mathrm{~cm}$ from the dentate line $(11,14)$, additional studies would be needed to explain the discrepancies in the interpretation of the clinical significance of ACF among previous studies.

Our results demonstrated that the patient physique was not associated with the length of the bowel segment from the middle Houston valve to the dentate line. For reasonably comparing the results from different studies, common criteria are required for defining the ACF counting area. Although additional studies are needed to confirm that the same results could be applied to western populations, we propose that the most appropriate counting area for ACFs during colonoscopy is from the middle Houston valve to the dentate line, because the middle Houston valve is an easily recognized landmark.

In conclusion, ACF were predominantly identified in the bowel segment from the middle Houston valve to the dentate line, and result of counting of the number of ACF was not affected depending on which of the two counting areas frequently used in previous ACF studies, were used. These results indicated that the discrepancies in the reports about the biological significance of ACF among previous studies may not be explained by differences in the criteria used for defining the ACF counting area, but other factors (e.g., race and/or behavioral characteristics), and warrant further investigation involving a larger group of patients of different races and behavioural features.

\section{Acknowledgements}

This study was supported in part by a Grant-in-Aid for research on the Third-Term Comprehensive Control Research for Cancer from the Ministry of Health, Labour and Welfare, Japan, to A. N.

\section{References}

1. Winawer SJ, Zauber AG, Ho MN, O'Brien MJ, Gottlieb LS Sternberg SS, Waye JD, Schapiro M, Bond J, Panish JF, et al: Prevention of colorectal cancer by colonoscopic polypectomy. The National Polyp Study Workgroup. N Engl J Med 329: 1977-1981, 1993.

2. Jemal A, Siegel R, Xu J and Ward E: Cancer statistics, 2010. CA Cancer J Clin 60: 277-300, 2010.

3. Bird RP: Observation and quantification of aberrant crypts in the murine colon treated with a colon carcinogen: Preliminary findings. Cancer Lett 37: 147-151, 1987.

4. McLellan EA and Bird RP: Aberrant crypts: Potential preneoplastic lesions in the murine colon. Cancer Res 48: 6187-6192, 1988.

5. McLellan EA, Medline A and Bird RP: Dose response and proliferative characteristics of aberrant crypt foci: Putative preneoplastic lesions in rat colon. Carcinogenesis 12: 2093-2098, 1991.
6. McLellan EA, Medline A and Bird RP: Sequential analyses of the growth and morphological characteristics of aberrant crypt foci: Putative preneoplastic lesions. Cancer Res 51: 5270-5274, 1991.

7. Pretlow TP, Barrow BJ, Ashton WS, O'Riordan MA, Pretlow TG, Jurcisek JA and Stellato TA: Aberrant crypts: Putative preneoplastic foci in human colonic mucosa. Cancer Res 51: 1564-1567, 1991.

8. Takayama T, Katsuki S, Takahashi Y, Ohi M, Nojiri S, Sakamaki S, Kato J, Kogawa K, Miyake H and Niitsu Y: Aberrant crypt foci of the colon as precursors of adenoma and cancer. $\mathrm{N}$ Engl J Med 339: 1277-1284, 1998.

9. Adler DG, Gostout CJ, Sorbi D, Burgart LJ, Wang L and Harmsen WA: Endoscopic identification and quantification of aberrant crypt foci in the human colon. Gastrointest Endosc 56: 657-662, 2002.

10. Hurlstone DP, Karajeh M, Sanders DS, Drew SK and Cross SS: Rectal aberrant crypt foci identified using high-magnification-chromoscopic colonoscopy: Biomarkers for flat and depressed neoplasia. Am J Gastroentrol 100: 1283-1289, 2005.

11. Seike K, Koda K, Oda K, Kosugi C, Shimizu K, Nishimura M, Shioiri M, Takano S, Ishikura H and Miyazaki M: Assessment of rectal aberrant crypt foci by standard chromoscopy and its predictive value for colonic advanced neoplasms. Am J Gastroenterol 101: 1362-1369, 2006.

12. Kim J, Ng J, Arozulllah A, Ewing R, Llor X, Carroll RE and Benya RV: Aberrant crypt focus size predicts distal polyp histopathology. Cancer Epidemiol Biomarkers Prev 17: 1155-1162, 2008.

13. Rudolph RE, Dominitz JA, Lampe JW, Levy L, Qu P, Li SS, Lampe PD, Bronner MP and Potter JD: Risk factors for colorectal cancer in relation to number and size of aberrant crypt foci in humans. Cancer Epidemiol Biomarkers Prev 14: 605-608, 2005.

14. Moxon D, Raza M, Kenney R, Ewing R, Arozullah A, Mason JB and Carroll RE: Relationship of aging and tobacco use with the development of aberrant crypt foci in a predominantly African-American population. Clin Gastroenterol Hepatol 3: 271-278, 2005.

15. Stevens RG, Swede H, Heinen CD, Jablonski M, Grupka M, Ross B, Parente M, Tirnauer JS, Giardina C, Rajan TV, et al: Aberrant crypt foci in patients with a positive family history of sporadic colorectal cancer. Cancer Lett 248: 262-268, 2007.

16. Sakai E, Takahashi H, Kato S, Uchiyama T, Hosono K, Endo H, Maeda S, Yoneda M, Taguri M and Nakajima A: Investigation of the prevalence and number of aberrant crypt foci associated with human colorectal neoplasm. Cancer Epidemiol Biomaekers Prev Res 20: 1918-1924, 2011.

17. Mutch MG, Schoen RE, Fleshman JW, Rall CJ, Dry S, Seligson D, Charabaty A, Chia D, Umar A, Viner J, et al: A multicenter study of prevalence and risk factors for aberrant crypt foci. Clin Gastroenterol Hepatol 7: 568-574, 2009.

18. Cho NL, Redston M, Zauber AG, Carothers AM, Hornick J, Wilton A, Sontag S, Nishioka N, Giardiello FM, Saltzman JR, et al: Aberrant crypt foci in the adenoma prevention with celecoxib trial. Cancer Prev Res 1: 21-31, 2008.

19. Hosono K, Endo H, Takahashi H, Sugiyama M, Sakai E, Uchiyama T, Suzuki K, Iida H, Sakamoto Y, Yoneda K, et al: Metformin suppresses colorectal aberrant crypt foci in a short-term clinical trial. Cancer Prev Res 3: 1077-1083, 2010.

20. Takayama T, Nagashima H, Maeda M, Nojiri S, Hirayama M, Nakano Y, Takahashi Y, Sato Y, Sekikawa H, Mori M, et al: Randomized double-blind trial of sulindac and etodolac to eradicate aberrant crypt foci and to prevent sporadic colorectal polyps. Clin Cancer Res 17: 3803-3811, 2011.

21. Ezuka A, Sakai E, Kawana K, Nagase H, Kakuta Y, Uchiyama S, Ohkubo H, Higurashi T, Nonaka T, Endo H, et al: Association between factors associated with colorectal cancer and rectal aberrant crypt foci in humans. Oncol Lett 10: 3689-3695, 2015.

22. Ohkubo H, Takahashi H, Yamada E, Sakai E, Higurashi T, Uchiyama T, Hosono K, Endo H, Taguri M and Nakajima A: Natural history of human aberrant crypt foci and correlation with risk factors for colorectal cancer. Oncol Rep 27: 1475-1480, 2012. 